Original Research Paper

\title{
Advising Approach to Enhance Students' Performance Level in Higher Education Environments
}

\author{
${ }^{1}$ Aya M. Mostafa, ${ }^{2}$ Ayman E. Khedr and ${ }^{1}$ A. Abdo \\ ${ }^{1}$ Department of Information Systems, Faculty of Computers and Information, Helwan University, Egypt \\ ${ }^{2}$ Department of Information Systems, Faculty of Computers and Information Technology, \\ Future University in Egypt, Egypt
}

Article history

Received: 08-11-2016

Revised: 03-04-2017

Accepted: 24-05-2017

Corresponding Author: Aya M. Mostafa

Department of Information

Systems, Faculty of Computers and Information, Helwan

University, Egypt

Email: ayaamar29@yahoo.com

\section{Introduction}

Higher Educational Institutions, nowadays, are facing many challenges in providing an interactive guiding system to support students during the course registration process, due to the speedy growth of students' number. In additions to, not all the students have the same skill level. There are four main skills for each student, First (K) Knowledge and Understanding, Second (I) Intellectual Skills, Third (P) Professional and Practical Skills, Finally (G) General and Transferable Skills. Students select the courses with no consideration of these skills which may affect their grades. Furthermore, there are external factors which controlled the course registration process e.g., (friends, suitable appointment and the professor of the subject). A fault selections courses, which may affect the changing courses ratio e.g., (add and drop). We will introduce a solution via The Proposed Advising Approach in order to overcome this problem.

Intended Learning Outcomes (ILOs) should be SMART (specific, measurable, applicable, realistic, time -based) for quality assurance of education process. ILOs has many benefits like:

- It is a good tool that supports decision making based on the extracted information
- It works as a framework for continuous improvement and evaluation in higher education environments

- It is used as a common language inside the educational institution

- It helps to get a clear vision for continuous development

- It helps to specify correct assessment tools for the good education process, necessary skills for courses and students had to be known

- It helps to take the right decision at the right time

Academic Advising Process (ADP) involves five main dimensions which are course choice, program choice, scheduling courses, life goals exploration and vocational goals exploration as shown in Fig. 1. The following points clarify the course choice dimension.

- What are available academic courses?

- Providing Information about courses regarding (Prerequisites, transferability, offered only at certain times, what are courses which meet graduation requirements? what is the appropriate sequence of student at the faculty?)

- Providing Information about rules and regulations faculty regarding course limit and examination

- Providing Information about evaluation way of academic courses 
- What are remedial academic course?

- What is academic course content?

- Providing Information about instructors and their teaching styles

- Test scores and high school record help to identify student's skill (O'Banion, 1994)

One of the first definitions of learning style was published in 1985 by Keefe, who defines it as: "Characteristic cognitive, affective and psychological behaviors that serve as relatively stable indicators of how learners perceive, interact with and respond to the learning environment." (Keefe, 1985; Brown, 2000), defined Style as: "Style is a term that refers to consistent and rather enduring tendencies or preferences within an individual". Lawson and Johnson (2002), defined learning style as: "A student's preferred way of acquiring and using information."

Several learning style models which assist in determining the students' learning style have been offered by researchers e.g., Riding, Apter, Jackson, Myers-Briggs, Allison and Hayes, Herrmann, Honey-Mumford and many more. However, there are six models in the learning styles which are well-known and widely available. Six models presented by Vark, Kolb, Rasi, Gregorc, Felder-Silverman and Dunn-Dunn as shown in Fig. 2.

The Kolb Learning Style Inventory (LSI) was used to measure the learning styles of students. Kolb's learning styles are defined by four levels: Diverger, Assimilator, Accommodator and Converger as shown in Table 1.

This paper is organized as follows: Section 2 describes the related studies in learning styles, section 3introducesthe proposed advising approach to enhance students' performance level in the educational process, section 4 describes the implementation of this approach using a case study from the real-world environment. Finally, in section 5 , the conclusions and future work are discussed.

\section{Related Work}

Several studies introduced different ideas for enhancing students' performance level in educational institutions to achieve effectiveness and efficiency of educational quality. So we briefly presented some of the valuable case studies in education environments. In (Hamada et al., 2011; Dung and Florea, 2013; Scott et al., 2014), they used an Index of Learning Style (ILS) to determine the suitable learning styles based on behavior analysis in a learning environment. Learning styles characteristic were active, reflective, sensing, intuitive, visual, verbal, global and sequential\}. Hamada et al. (2011), discussed the utilizing of a social bookmarking website, e.g., www.tagme1.com to collect hints about the learners' behavior through learners are browsing/exploring their favorite web pages. Dung and Florea (2013), introduced the domain ontology in e- learning environments. They also introduced the proposed an architecture for building a personalized a multi-agent e-learning system that provided courses for better personalization during pre-determining and reviewing students' learning styles. Scott et al. (2014), utilized the association rules to discover relationships between how students use Scrum and their learning style. A virtual world equipped with Scrum artifacts, Virtual Scrum, supported the Scrum process during the capstone project in the context of a Software Engineering course at UNICEN. This tool helped to record all student activities, e.g., the time spent on User Stories.

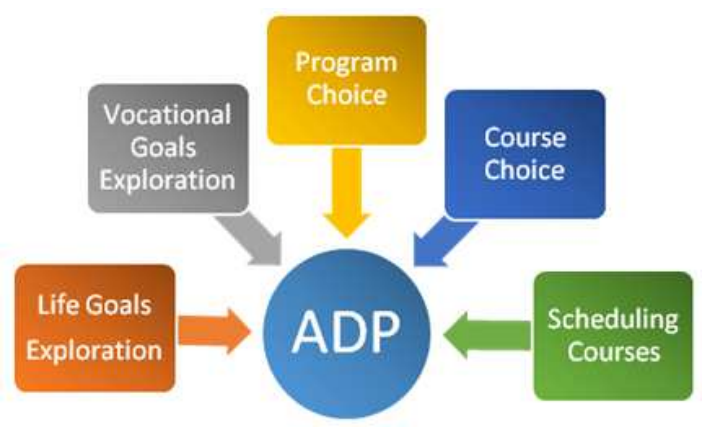

Fig. 1. Academic Advising Process (ADP) dimensions

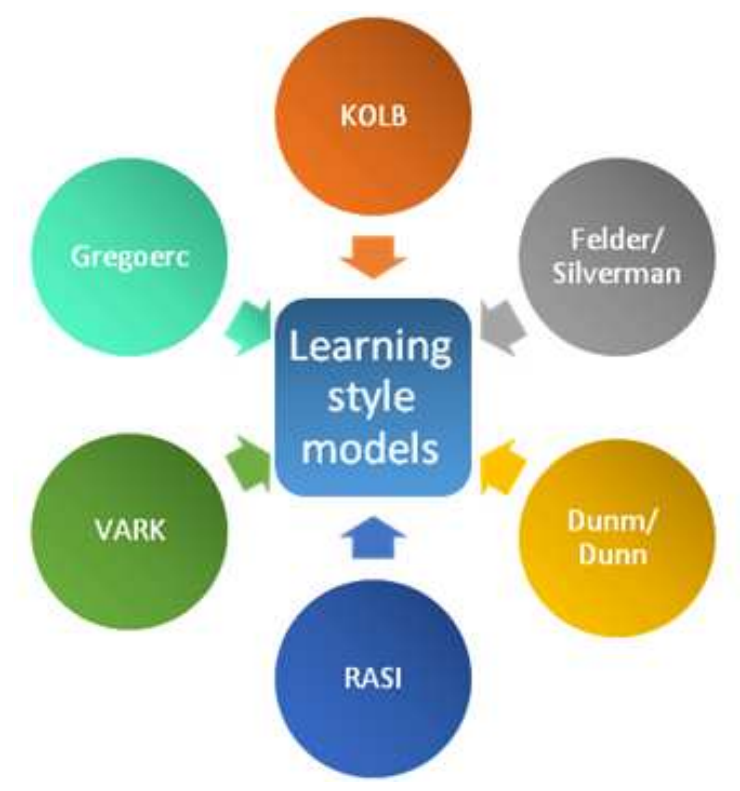

Fig. 2. Six prominent learning style models; Source: Hawk and Shah (2007)

Table 1. Features of learning styles

\begin{tabular}{ll}
\hline Learning style & They best learn through \\
\hline The Diverger & Feeling and watching \\
The Assimilator & Thinking and watching \\
The Converger & Thinking and doing \\
The Accommodator & Feeling and doing \\
\hline
\end{tabular}

Source: Manochehr (2006) 
After studying these researchers, it has been found that the main advantage of these researchers was using an Index of Learning Style (ILS). It is a prevalent instrument as well as user-friendly. However, the main disadvantage of these researchers, it is using the small sample size as it contained a few numbers of learners which led to inaccurate results.

In (Milicevic et al., 2011; Al-Saud, 2013; Elkalmi et al., 2015; Gurpinar et al., 2010; O'Mahony et al., 2016), they used the higher data set in order to reach accurate results. Milicevic et al. (2011), introduced proposed recommendation module "Protus" which assist learners for programming tutoring system during determining learners' knowledge level and their interests automatically. Al-Saud (2013), aimed to investigate three factors which included learning style preferences, gender and previous academic performance of students to improve students 'performance. Elkalmi et al. (2015), aimed to enhance learning experiences and improve the quality teaching for pharmacy students at Malaysia University during integration between teaching styles and students' preference in learning styles. Gurpinar et al. (2010), aimed to determine the suitable learning styles of medical students during measuring satisfaction factor for various education methods and academic achievement in them. During the academic year of 2008-2009 were carried out five theoretical block exams and five PBL exams. O'Mahony et al. (2016), aimed to investigate the relationship between learning style preferences, anatomy and clinical skills assessment performance at in Irish medical school.

\section{The Proposed Advising Approach}

In this section, we aim to provide extremely valuable information to make improvement in the educational process. The Proposed advising approach aims to enhance students' performance level during suggesting the suitable courses for the student based on a set of criteria, including his skills, required types of courses..., etc. It consists of four basic stages: The first stage is about capturing educational data. The second stage includes processing (determine, sort, build and identify) educational data. The third stage involves identifying available tracks. Furthermore, selecting the suitable track according to student skill level. Finally, evaluates the student performance.

\section{Stage 1: Gather the Required Data}

At this stage, the educational data are captured which is organized as follows courses data description as shown in Fig. 2-4 and students' data description.

\section{Courses Data Description}

In Higher Education Environments (HEE), course specification involves Intended Learning Outcomes
(ILOs), which has four main components. First (A) Knowledge and Understanding, Second (B) Intellectual Skills, Third (C) Professional and Practical Skills. Finally (D) General and Transferable Skills. ILOs is the final results which Higher Education Environments (HEE) seeks to achieve through its various courses and associated with the mission. In addition to reflecting National Academic Reference Standard (NARS) as shown in Fig. 3.

In addition to, courses are divided into two types obligatory and elective. Furthermore, elective and obligatory courses are organized into three kinds as follows specialization, university and faculty as shown in Fig. 4.

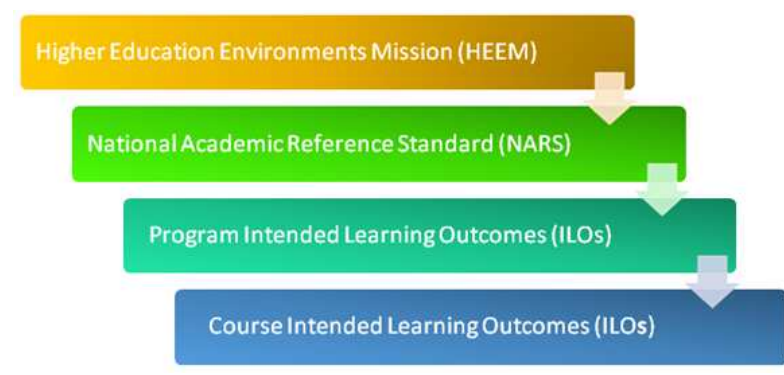

Fig. 3. ILOs, NARS and Mission Institution

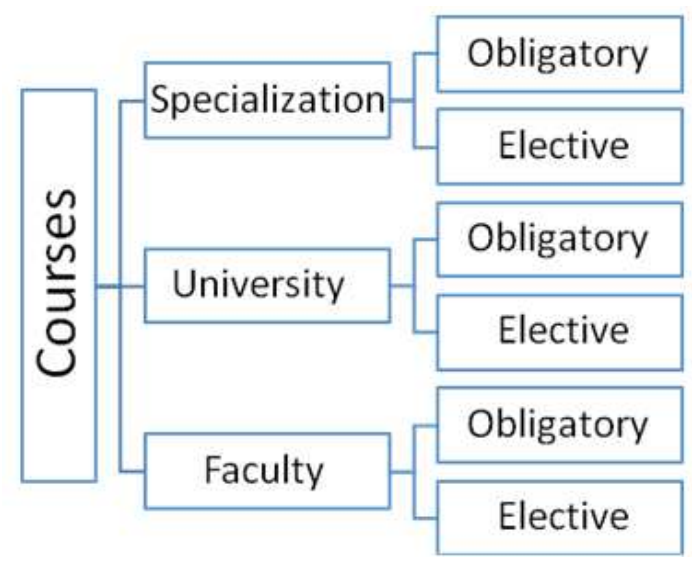

Fig. 4. Courses types

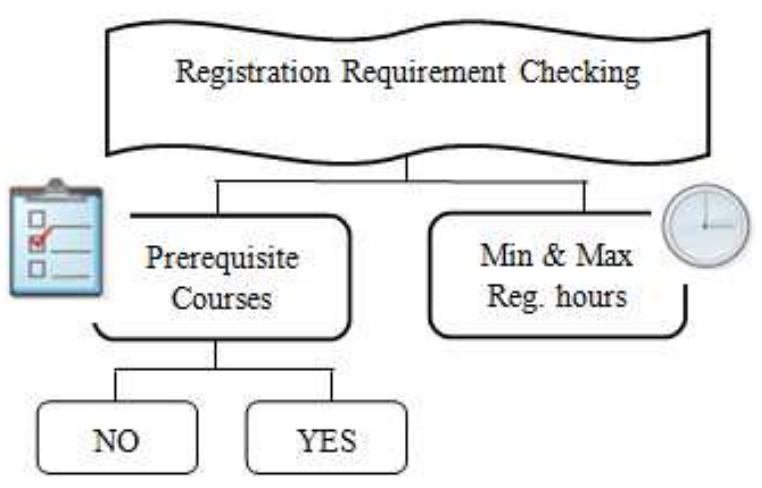

Fig. 5. Registration requirement checking 
There are two requirements which check before registration process. Prerequisite courses (YES and No) done, as well as minimum and maximum for the registration hours as shown in Fig. 5.

\section{Students' Data Description}

Students' data include checking student performance in the level_1 (pass or fail). Furthermore, the grade for the student (Excellent, Very Good, Good and Bad). In the case of the student is passed, then start the registration process. Not all the students have the same skill level. There are four main skills for each student, First (K) Knowledge and Understanding, Second (I) Intellectual Skills, Third (P) Professional and Practical Skills, Finally (G) General and Transferable Skills as shown in Fig. 6.

\section{Stage 2: Processing Educational Data}

The second stage process the educational data (courses data and students' data), there are three main steps. The first step is about determining all the possible arrangements of the four skills $\{\mathrm{K}, \mathrm{I}, \mathrm{P}$ and $\mathrm{G}\}$. The second step involves sorting the skills list. In addition to, building the decision tree that has been implemented. The third step includes identifying student skills based on test his skills. As shown in Fig. 7.

\section{Determine All the Possible Arrangements}

"How many different ways can you arrange the three elements from a set of the three elements $\{\mathrm{A}, \mathrm{B}$ and C\}?" To determine all the possible arrangements of the three elements $P_{-} r^{\wedge} n=n ! /(n-r)$ ! (Chuan-Chong and Khee-Meng, 2005) $P 3^{\wedge} 3=3 ! /(3-3) !=6$ possible. Where Number of sample points in the set (n) Number of sample points in each permutation (r) Number of permutations ( $n$ things taken $r$ at a time).The full list of possible permutations would be $\{\mathrm{ABC}, \mathrm{ACB}, \mathrm{CAB}$, $\mathrm{BAC}, \mathrm{BCA}$ and $\mathrm{CBA}\}$.The output of this part is a very important indicator that should be considered when applying the decision tree.

\section{Sort the Skills and Build the Decision Tree}

Rosen (2011), discussed the complexity of a sort based on binary comparisons is measured in terms of the number of such comparisons used. The largest number of binary comparisons ever needed to sort a list with [n] elements gives the worst-case performance of the algorithm. The most comparisons used equals the longest path length in the decision tree representing the sorting procedure. In other words, the largest number of comparisons ever needed is equal to the height of the decision tree. Because the height of a binary tree with [n!] leaves is at least [ $\log n$ !]. A sorting algorithm based on binary comparisons requires at least [log $n$ !] comparisons. The decision tree for sorting three distinct elements is built which is shown in Fig. 8.

\section{Identify the Student Skills}

At this step, includes identifying student skills according to test his skills. Due to determining a suitable course for a student based on his skills. A Test his Skill measures four factors, which includes (K) Knowledge and Understanding, (I) Intellectual Skills, (P) Professional and Practical Skills, as well as (G) General and Transferable Skills. Each factor contains set of questions. After executing this test, then we find that there are 4 grades for each student.

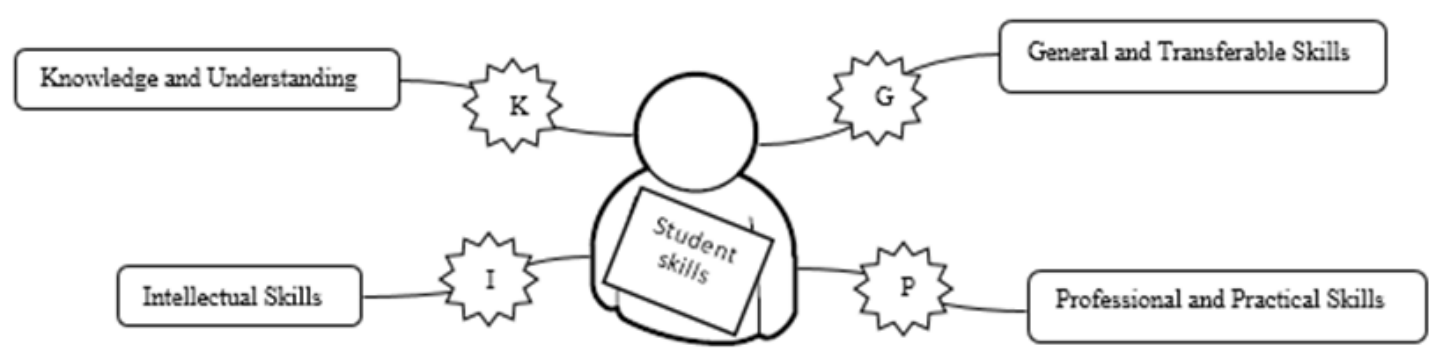

Fig. 6. Student Skills
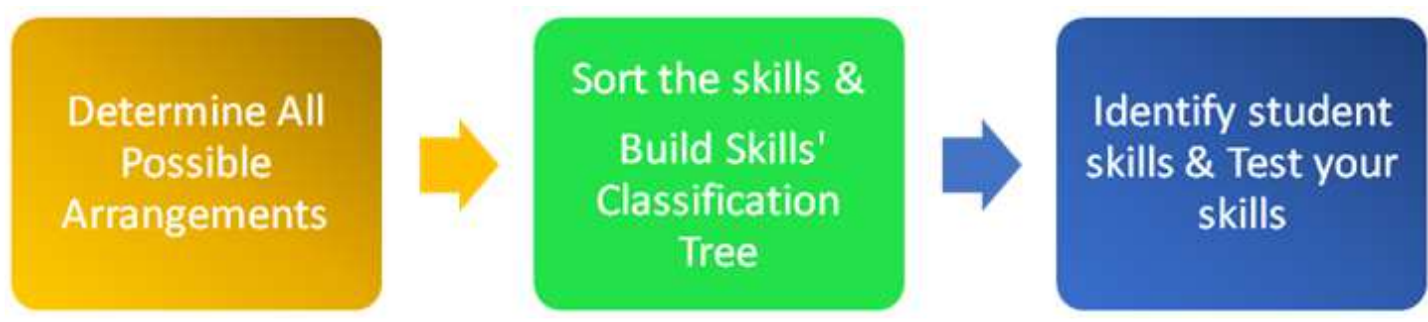

Fig. 7. Main Steps for Processing Educational Data 


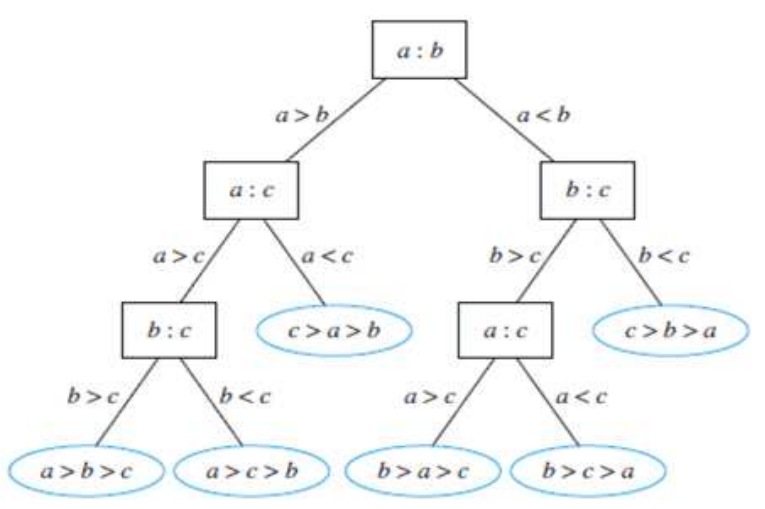

Fig. 8. Decision tree for sorting three distinct elements; Source: Rosen (2011)

\section{Stage 3: Suggestion for Student Tracks}

The Third stage, draw the track of a suitable course. The following steps from 1 to 5 present the pseudo code to suggest courses for a student according to his skills:

- Input array skills (by output of decision tree)

- Input calculates student skills (by, test your skills)

- Match student skills with decision tree leaf

- The input required number of courses (by student)

- Determine a set of courses according to the number of courses (by student)

Finally, evaluates the student' performance in order to, identify whether our approach is moving towards the achievement of its objective or not. If the student' performance is not improved, return to stage one or two as appropriate.

\section{Finding and Analysis Results}

In this section, we discuss the details of the experiment in which the proposed advising approach has been applied on investment data in the educational sector. In particular, we will show how courses can be suggested for the student according to his skills. Here we will go through all stages of the proposed advising approach in the faculty of Commerce and Business Administration, Business Information System program (BIS) at Helwan University, Egypt.

\section{Stage 1: Gather the Required Data}

In this stage, the educational data of the Business Information System program (BIS) are captured which is organized as follows courses data description and students' data description.

\section{Courses Data Description}

In the Business Information System program (BIS), course specification involves Intended Learning
Outcomes (ILOs), which has four main components. First, (A) Knowledge and Understanding [25\%]. Second, (B) Intellectual Skills [25\%]. Third, (C) Professional and Practical Skills [35\%]. Finally, (D) General and Transferable Skills [15\%].

In addition to, courses are divided into two types obligatory and elective. The (BIS) program includes 35 Obligatory courses and 22 elective courses. Each student needs to graduate from BIS program 35 Obligatory courses and 8 elective courses as shown in Table 3. Furthermore, elective and obligatory courses are organized into three kinds as follows specialization, university and faculty. The BIS program provides 15 specialization courses, 3 university courses and 17 faculty courses in the obligatory courses. Additionally, 8 specialization courses, 5 university courses and 9 faculty courses in the elective courses. Each student needs to 3 specialization courses, 2 university courses and 3 faculty courses in the elective courses over 4 years.

There are two requirements which check before registration process. Prerequisite courses (YES and No) done as well as minimum and maximum of the registration hours. The student can register any course, after passing the previous requirements. The student gets GPA "Bad", who allows registration 4 courses, but 6 courses for the student gets GPA greater than "Bad".

A Questionnaire model for course specification is used to rank Intended Learning Outcomes (ILOs) of the BIS Program based on their importance. Due to the course evaluation is a very important factor that should be considered when applying a new approach. After our analysis this Questionnaire, it has four central components which are Knowledge and Understanding, Intellectual Skills, Professional and Practical Skills, as well as General and Transferable Skills.

In the Knowledge and Understanding, there are 14 courses (e.g., Introduction to Computer, Medical and Health Information Systems, Introduction to Computer, Medical and Health Information Systems, Accounting1, Principles of Law, Principles of Economics, etc.). In the Intellectual Skills contain14courses (e.g., Creative Thinking, Media and Mathematics for Business, Principles of Statistics, Economic Planning, Operations Research, Software Engineering, etc.). In the Professional and Practical Skills involve 20 courses (e.g., System Analysis 2, Management Information Systems, Computer Networks, E Commerce Sites, Advanced E Commerce, Human Rights, Money and Banking, Accounting 2, Cost Accounting, etc.). In General and Transferable Skills include 8 courses (e.g., International Relations, Marketing, Human Resource Management, Management of Specialized Institutions, etc.).

Second level courses are classified into two classes. The first class is obligatory courses and the second class is elective courses. Obligatory courses are classified according to four components. The first component 
stands for Knowledge and Understanding comprise Database, Programming1 and E-Commerce. The second component denotes Intellectual Skills involve System Analysis 1, Decision Making Support Systems, Data Security and Principles of Statistics. The third component indicates Professional and Practical Skills contain Programming 1, Management Information Systems, Computer Networks, Money and Banking, Production and Operations Management, Cost Accounting and Accounting for Partnerships. The fourth component is about General and Transferable Skills include English 2, Marketing and Human Resource Management.

Elective courses classify according to four components. The first component stands for
Knowledge and Understanding includes Principles of Law, Medical and Health Information Systems, Foreign Trade, Professional Ethics, Internet Application and Public Finance. The second component denotes Intellectual Skill involve Media, Creative thinking and Economic Planning. The third component indicates Professional and Practical Skills contain Accounting Information Systems, Material Management and Information Economics. The fourth component is about General and Transferable Skills include International Relations, Communications and Negotiation skills and Management of Specialized Institutions. As shown in Fig. 9.
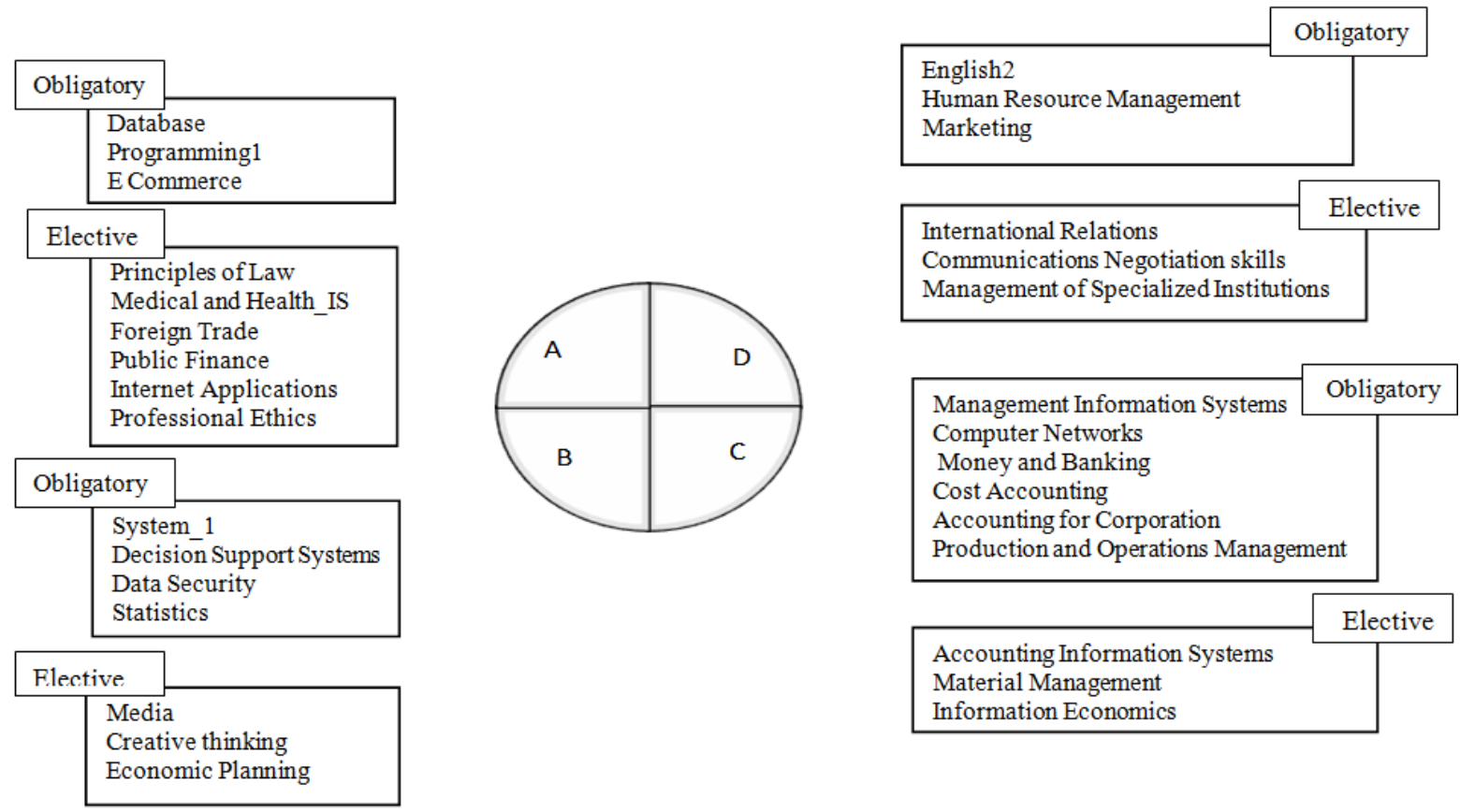

Fig. 9. Elective courses and Obligatory courses for the Second level according to the ILOs

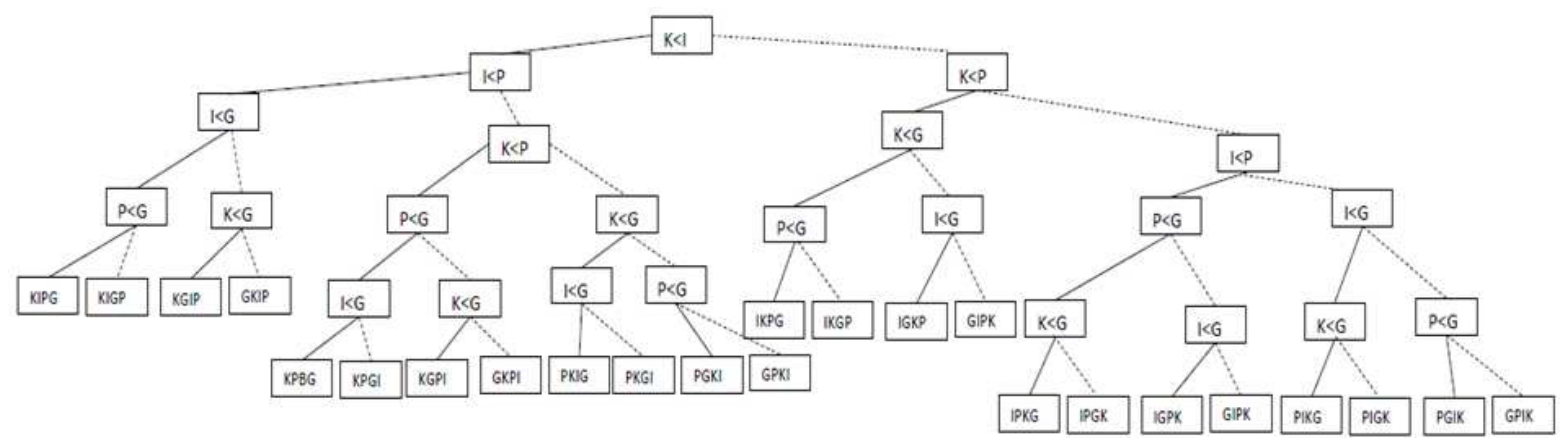

Fig. 10. Decision tree for possible arrangements of the four skills

Table 2. Evaluation grade of student

\begin{tabular}{lllll}
\hline Word & Excellent & Very Good & Good & Bad \\
\hline Grade & $85<=$ grade $<=100$ & $75<=$ grade $<85$ & $65<=$ grade $<75$ & $50<=$ grade $<65$ \\
\hline
\end{tabular}




\section{Students' Data Description}

An evaluation grade of the student which are studying in a Business Information System program (BIS), is displayed by the word program. Grade range of these words is represented in Table 2. Not all the students have the same skill level. There are four main skills for each student, First (K) Knowledge and Understanding, Second (I) Intellectual Skills, Third (P) Professional and Practical Skills, Finally (G) General and Transferable Skills. These skills lead to differing grade between students. Additionally the numbers of courses registration.

\section{Stage 2: Processing Educational Data}

At this stage, includes processing (determine, sort, build and identify) educational data (courses data and students' data).

\section{Determine All the Possible Arrangements}

"How many different ways can you arrange the four skills from a set of the fourskills $\{\mathrm{K}, \mathrm{I}, \mathrm{P}$ and $\mathrm{G}\}$ of the student?". To determine all the possible arrangements of the fourskills $P_{-} r^{\wedge} n=n ! /(n-r)$ ! (Chuan-Chong and Khee-Meng, 2005) ${ }^{-}{ }_{-} 4^{\wedge} 4=4 ! /(4-4) !=24$ possible. Where Number of sample points in the set (n) Number of sample points in each permutation (r) Number of permutations ( $\mathrm{n}$ things taken $\mathrm{r}$ at a time). The full list of possible permutations would be \{KIPG, KIGP, KPIG, KPGI, KGIP, KGPI, IKPG, IKGP, PKIG, PKGI, GKIP, GKPI, GPIK, PGIK, GIPK, IGPK, PIGK, IPGK, GPKI, PGKI, GIKP, IGKP, PIKG, IPKG $\}$. The output of this part is a very important indicator that should be considered when applying the decision tree.

\section{Sort the Skills, Build the Decision Tree and Identify} the Student Skills

The decision tree is built which is shown in Fig. 10. The following points clarify the decision tree:

- The dashed line represents NO direction

- The continuous line represents YES direction

- Sorting the four skills works by comparing and rearranging them

We put the smallest skill at the start of the list, then the next smallest skill in the second position in the list and so on until the list is in order.

After our making a decision tree all the possible arrangements of the four skills are as follows: $\{\mathrm{KIPG}$, KIGP, KPIG, KPGI, KGIP, KGPI, IKPG, IKGP, PKIG, PKGI, GKIP, GKPI, GPIK, PGIK, GIPK, IGPK, PIGK, IPGK, GPKI, PGKI, GIKP, IGKP, PIKG, IPKG\}. Then, the student starts the test to evaluate each skill individually.

\section{Stage 3: Suggestion for Student Tracks}

The Third stage, the tracks of the suitable courses are drawn as shown in Fig. 11. The following steps from 1 to $5 \%$ the pseudo code to suggest courses for a student according to his skills:

- Input array skills (by output of decision tree)

- Input calculates student skills (by, test your skills)

- Match student skills with decision tree leaf

- The input required number of courses (by student)

- Determine a set of courses according to the number of courses (by student)

\section{Example}

- Array skills (by output of decision tree) are as follows: \{KIPG, KIGP, KPIG, KPGI, KGIP, KGPI, IKPG, IKGP, PKIG, PKGI, GKIP, GKPI, GPIK, PGIK, GIPK, IGPK, PIGK, IPGK, GPKI, PGKI, GIKP, IGKP, PIKG, IPKG\}

- Student skills (by, test your skills) is $\{\mathrm{K}, \mathrm{I}, \mathrm{G}$ and $\mathrm{P}\}$

- Match student skills with decision tree leaf

- The student registers 4 courses

- Display suggest courses for a student according to his skills:

- Medical Health IS, Law, Public Finance, Foreign Trade

- Medical Health IS, Law, Public Finance, Prof. Ethics

- Medical Health IS, Law, Public Finance, Internet App

\section{Stage 4: Evaluation}

At this stage, in order to evaluate the Proposed Advising Approach, we conducted 2 tests, Pre_Test before implementing the Proposed Advising Approach and Post_Test after applying it, then we compared the results of 2 tests (Pre_Test and Post_Test). The sample size consisted of 886 students who were classified as 864 students passed, 22 students failed depending on their performance in the level 1 during the 2015-2016 from the faculty of Commerce and Business Administration, Business Information System program (BIS) at Helwan University, Egypt. The Proposed Advising Approach was tested by 864 students, but the 22 students failed, who ignored when applying it.

Pre_Test measured four skills, which included (K) Knowledge and Understanding, (I) Intellectual Skills, (P) Professional and Practical Skills, as well as (G) General and Transferable Skills. After our analysis in this test, we found that the number of students was higher for (P) Professional and Practical skills $(30 \%)$, than (K) Knowledge and Understanding skills (27\%), then (I) 
Intellectual Skills $(22 \%)$, then $(\mathrm{G})$ General and Transferable Skills $(21 \%)$. Table 3 provides details.

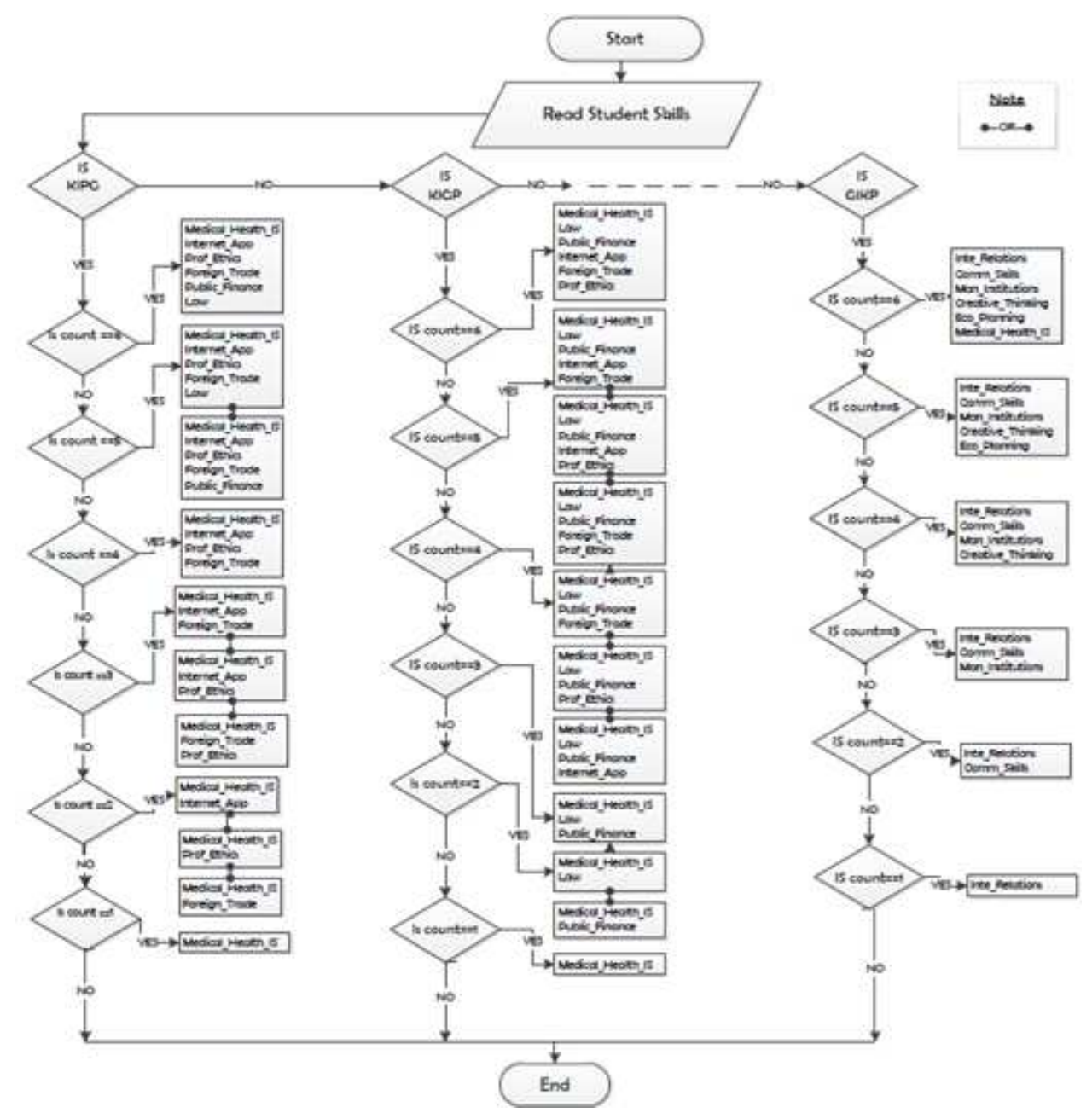

Fig. 11. Tracks of the suitable courses

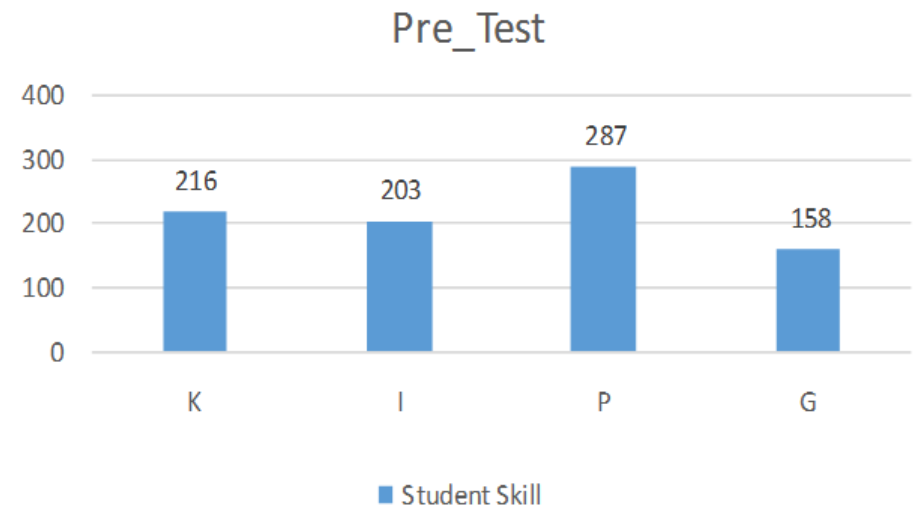

Fig. 12. The pre test results

Table 3. The Results of Pre Test

\begin{tabular}{lllll}
\hline Student Skill & K & I & P & G \\
\hline Sample size & 233 & 191 & 258 & 182 \\
Percentage \% & $27 \%$ & $22 \%$ & $30 \%$ & $21 \%$ \\
\hline
\end{tabular}

Table 4. The Results of Post Test

\begin{tabular}{lllll}
\hline Student Skill & K & I & P & G \\
\hline Sample size & 216 & 207 & 268 & 173 \\
Percentage \% & $25 \%$ & $24 \%$ & $31 \%$ & $20 \%$ \\
\hline
\end{tabular}




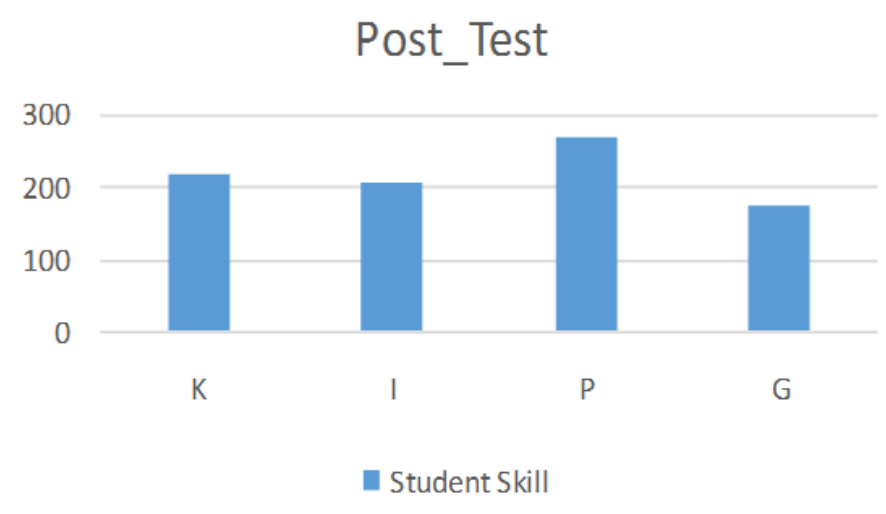

Fig. 13. The post_test results

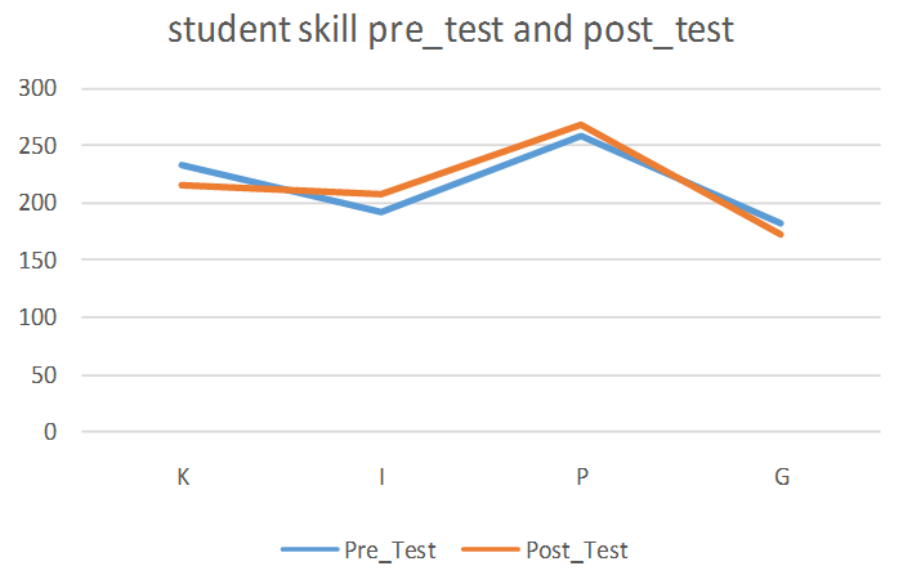

Fig. 14. Comparing between pre_test and post_test

The Fig. 12 illustrates the classification of 864students according to their skills after Pre_Test. There are four skills for each student, which includes (K) Knowledge and Understanding, (I) Intellectual Skills, (P) Professional and Practical Skills, as well as (G) General and Transferable Skills.

We carried out the Post_test after suggestion courses for a student according to his skills. After our analysis in this test, we found that the number of students was higher for (P) Professional and Practical skills $(31 \%)$, than $(\mathrm{K})$ Knowledge and Understanding skills $(25 \%)$, then (I) Intellectual Skills (24\%), then (G) General and Transferable Skills (20). We have achieved the first objective of the Intended Learning Outcomes (ILOs) of BIS Program. However, the three other components are close from achievement. Table 4 provides details.

The Fig. 13 illustrates the classification of 864 students according to their skills after Post_Test. There are four skills for each student, which includes (K) Knowledge and Understanding, (I) Intellectual Skills, (P) Professional and Practical Skills, as well as (G) General and Transferable Skills.
The Fig. 14 shows the final results of comparing between pre_test and post_test for 864 students according to their skills. $79 \%$ of students, enhance the performance, this number shows that the Proposed Advising Approach is successful and going in the correct direction. The reasons for the $21 \%$ unmatched results include.

\section{Conclusions and Future Work}

In this study, we proposed an intelligent advising approach in the higher educational system. It recommends useful advice and information about the tracks of the available courses for the students, in order to select suitable courses according to student skills. The proposed approach has been applied in the faculty of Commerce and Business Administration, Business Information System program (BIS) at Helwan University, Egypt and proved its applicability for advising systems based on the presented results. Our future work includes enhancing accuracy percentage of the proposed system in order to get more accurate outcomes and reach more effective and efficient decisions at the right time. It will also be very useful to add other styles for a student to identify his skills. As 
Students' skills will be measured in the Intended Learning Outcomes (ILOs) according to distribute the questions in four sets, each set represents a difficulty level from easy to hard.

\section{Author's Contributions}

Aya M. Mostafa: Contributed in all parts of the paper, the idea, the review part, the experiment, writing the paper and revising the paper.

Ayman E. Khedr: Contributed in all parts of the paper, the idea, the review part, the experiment, writing the paper and revising the paper.

A. Abdo: Contributed in all parts of the paper, the idea, the review part, the experiment, writing the paper and revising the paper.

\section{Ethics}

This article is original and contains unpublished material. The corresponding author confirms that all of the other authors have read and approved the manuscript and no ethical issues involved.

\section{References}

Al-Saud, L.M.S., 2013. Learning style preferences of first-year dental students at King Saud University in Riyadh, Saudi Arabia: Influence of gender and GPA. J. Dental Educ., 77: 1371-1378. PMID: 24098042

Brown, H.D., 2000. Principles of Language Learning and Teaching. 4th Edn., White Plains, Longman, ISBN-10: 130178160, pp: 352.

Chuan-Chong, C. and K. Khee-Meng, 2005. Permutations and combinations.

Dung, P.Q. and A.M. Florea, 2013. Adaptation to learners' learning styles in a multi-agent e-learning system. Internet Learn., 2: 11-20.

Elkalmi, R.M., A.K.M. Alshami, A. Ahmad, M. Umair and N.S.A.R. Khan et al., 2015. Assessment of learning style preferences of pharmacy students: Findings from public university of Malaysia. Ind. J. Pharmaceutical Educ. Res., 49: 266-271.

DOI: 10.5530/ijper.49.4.4

Gurpinar, E., M.K. Alimoglu, S. Mamakli and M. Aktekin, 2010. Can learning style predict student satisfaction with different instruction methods and academic achievement in medical education? Adv. Physiol. Educ., 34: 192-196.

DOI: 10.1152 /advan.00075.2010
Hamada, A.K., M.Z. Rashad and M.G. Darwesh, 2011. Behavior analysis in a learning environment to identify the suitable learning style. Int. J. Comput. Sci. Inform. Technol., 3: 48-59. DOI: $10.5121 /$ ijcsit.2011.3204

Hawk, T.F. and A.J. Shah, 2007. Using learning style instruments to enhance student learning. Decision Sci. J. Innovative Educ., 5: 1-19. DOI: $10.1111 /$ j.1540-4609.2007.00125.x

Keefe, J.W., 1985. Assessment of learning style variables: The NASSP task force model. Theory Pract., 24: 138-144.

DOI: $10.1080 / 00405848509543162$

Lawson, A.E. and M. Johnson, 2002. The validity of Kolb learning styles and neo-Piagetian developmental levels in college biology. Stud. Higher Educ., 27: 79-90. DOI: $10.1080 / 03075070120099386$

Manochehr, N.N., 2006. The influence of learning styles on learners in e-learning environments: An empirical study. Comput. Higher Educ. Econom. Rev., 18: 10-14.

Milicevic, A.K., B. Vesin, M. Ivanovic and Z. Budimac, 2011. E-learning personalization based on hybrid recommendation strategy and learning style identification. J. Comput. Educ., 56: 885-899. DOI: 10.1016/j.compedu.2010.11.001

O'Banion, T., 1994. An academic advising model. NACADA J., 42: 62-64.

O'Mahony, S.M., A. Sbayeh, M. Horgan, S. O'Flynn and C.M. O'Tuathaigh, 2016. Association between learning style preferences and anatomy assessment outcomes in graduate-entry and undergraduate medical students. Anatomical Sci. Educ., 9: 391-399. DOI: 10.1002 ase. 1600

Rosen, K.H., 2011. Discrete Mathematics and its Applications. 7th Edn., McGraw-Hill Education, New York, ISBN-10: 0073383090, pp: 1072.

Scott, E., G. Rodríguez, Á. Soria and M. Campo, 2014. Are learning styles useful indicators to discover how students use Scrum for the first time? Comput. Human Behav., 36: 56-64.

DOI: $10.1016 /$ j.chb.2014.03.027 